\title{
Obesity in Renal Transplantation
}

\author{
Maria Quero ${ }^{a, b, c}$ Nuria Montero ${ }^{a, b}, c$ Inés Rama ${ }^{a, b}$ Sergi Codina ${ }^{a, b}$ \\ Carlos Couceiro $^{a}$ Josep M. Cruzado ${ }^{a, b}, c$
}

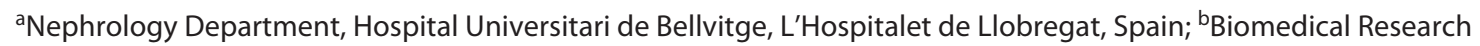
Institute (IDIBELL), Hospital Duran i Reynals, L'Hospitalet de Llobregat, Spain; 'Facultat de Medicina i Ciències de la

Salut, Universitat de Barcelona, L'Hospitalet de Llobregat, Spain

\section{Keywords}

Review · Kidney transplantation · Obesity

\begin{abstract}
Background: Data from the WHO show an increasing rate of overweight and obesity in general population in the last decades. This increase in obesity also affects population with end-stage renal disease (ESRD) and kidney transplant (KT) candidates. Summary: In this review, we focused on how obesity impacts on KT stages: access to KT and outcomes of KT candidates; how to reduce weight and its consequences; short and long-term outcomes in obese recipients and the impact of weight variations; and the implications of obesity in living donor KT. We searched MEDLINE, EMBASE, and Cochrane Central Register of Controlled Trials until November 30,2020 . We selected systematic reviews and meta-analyses and randomized clinical trials. When no such reports were found for a topic, observational studies were included in the assessment. Key Messages: Although obesity is a risk factor to present worst outcomes after KT, several studies have demonstrated a survival benefit compared to patients who continue on dialysis. There is a need for a public health campaign to raise awareness in $\mathrm{KT}$ candidates and to highlight the importance of self-care, increasing exercise, healthy diet, and weight loss.

(c) 2021 S. Karger AG, Basel
\end{abstract}

karger@karger.com www.karger.com/nef

(c) 2021 S. Karger AG, Basel

Karger'

\section{Introduction}

According to data from the $\mathrm{WHO}$, the prevalence of obesity, described as BMI $\geq 30 \mathrm{~kg} / \mathrm{m}^{2}$ and/or body fat $>25 \%$ in men and $>35 \%$ in women, has risen in general population from 5 to $10 \%$ in men and from 8 to $14 \%$ in women from 1980 to 2008. In 2016, 2 billion adults had overweight worldwide, and 650 million of them were classified as obese [1]. This increase in obesity also affects population with end-stage renal disease (ESRD) and kidney transplant (KT) candidates [2]. Moreover, a higher prevalence and incidence of obesity has been described in ESRD patients than in the general population in the USA [3].

Obesity is a major cardiovascular risk factor (CVRF), frequently associated with other CVRFs such as hypertension, insulin resistance, dyslipidaemia, and atherosclerosis and strongly related to metabolism disorders. More than $75-80 \%$ of KT recipients present at least one CVRF, and even though transplantation decreases the risk of death and cardiovascular events in relation to dialysis, cardiovascular disease remains one of the leading causes of death ( $17 \%$ cases) in KT recipients [4]. This review will focus on major issues related to obesity in potential candidates, recipients, and donors.

Contribution from the CME course of the DIABESITY Working Group of the ERA-EDTA, Alcorcón (Madrid), Spain, November 15-16, 2019.

Correspondence to:

Josep M. Cruzado, jmcruzado@bellvitgehospital.cat 


\section{Methods}

To assess the impact of obesity in KT recipients, we searched MEDLINE (via OVID), EMBASE (via OVID), and Cochrane Central Register of Controlled Trials until November 30, 2020. No language restrictions were done. We selected systematic reviews and meta-analyses and randomized clinical trials. When no such reports were found for a topic, observational studies were included in the assessment.

\section{Discussion}

\section{Obesity Measurement}

According to the WHO [5], obesity is defined as BMI $\geq 30 \mathrm{~kg} / \mathrm{m}^{2}$ and/or an excess of adiposity: when body fat exceeds $25 \%$ in men and $35 \%$ in women. There are different strategies for measuring it. BMI, defined as the relation between weight in kilograms $(\mathrm{kg})$ and height in metres squared $\left(\mathrm{m}^{2}\right)$, is the most used anthropometric tool, but it does not provide information about muscle mass and fluid status, and it is not able to distinguish sarcopenia from adiposity and visceral fat accumulation. Okorodudu et al. [6] published a meta-analysis including 31,968 subjects, and they showed that BMI $>30 \mathrm{~kg} / \mathrm{m}^{2}$ underestimates excess adiposity, since it has a low sensitivity (42\%) and a high specificity (97\%).

Despite these limitations, $\mathrm{BMI}$ is the most widely used anthropometric measure of obesity. There are other anthropometric measures of abdominal obesity, such as waist circumference or wait-to-hip ratio, considered better predictors of all-cause mortality in general population and also in ESRD and KT. Most of the patients with BMI $>35$ show elevated waist circumference, so its measurement may be redundant in this particular situation [7].

The measurement of body composition represents a valuable tool to assess nutritional status. Bioelectrical impedance analysis and dual-energy X-ray absorptiometry are considered useful methods for its evaluation in general population [8]. In clinical practice, bioelectrical impedance analysis is able to monitor body fluid compartments and nutritional status. However, the observed inter- and intraindividual variability as a consequence of changes in fat-free mass occurring with growth, maturation, ageing, and disease states is a relevant limitation [8]. On the other hand, visceral adipose tissue (VAT) is considered to be more closely associated with obesity-related diseases than BMI, waist circumference, or wait-to-hip ratio. The main limitation is that the "gold standard" techniques for measuring VAT are CT and MRI, and the fact that limits its use is because of the radiation exposure associated with CT and the cost of both techniques [9]. Nevertheless, in KT patients, Von Düring et al. [9] described the association between VAT, plasma glucose concentrations, and insulin resistance by a non-invasive and harmless method using a new software applied on dual-energy X-ray absorptiometry scans.

\section{Obesity and Access to KT}

Obesity in ESRD

Many epidemiological studies have demonstrated the "reverse epidemiology" effect between classic CVRF and mortality in some groups of patients such as elderly, hospitalized patients, some malignancies, and haemodialysis (HD) patients [10]. In terms of patient survival, KT is the best renal replacement therapy in patients with ESRD. Regarding obese KT candidates, though they show worse $\mathrm{KT}$ outcomes than non-obese, a survival benefit with KT compared to dialysis has been shown in some studies [11] with 2- to 5-year follow-up. This benefit seems to disappear in patients with $\mathrm{BMI}>40 \mathrm{~kg} / \mathrm{m}^{2}[11,12]$.

\section{Guideline Recommendations}

There are 4 major KT guidelines regarding this CVRF with general recommendations, without including any specific advice. The recently published European Renal Best Practice guidelines [13] only recommend weight loss in obese patients, and the Kidney Disease Improving Global Outcomes (KDIGO) guidelines [14] suggested that weight reduction before the surgical procedure does not provide as much beneficial effect as could be expected in general population. Other guidelines such as the UK Renal Association [12] and the Kidney Health Australia Caring for Australasians with Renal Impairment [15] conclude that benefits of $\mathrm{KT}$ are doubtful in potential candidates with BMI $>40 \mathrm{~kg} / \mathrm{m}^{2}$.

\section{What Are We Doing?}

In order to understand how nephrologists manage obesity in the setting of CKD and ESRD, 2 surveys have been published. Stenvinkel et al. [16] developed a survey that was posted on the NDT-E website with participation of 399 nephrologists around the world, mostly from Europe. The main findings of the survey were that in $30 \%$ of centres, there was not a true BMI cutoff to enable candidates to be included in the waiting list. However, a BMI cutoff of $\leq 35$ was used in $29 \%$ of centres and $\leq 30$ in other $27 \%$. A survey was also performed by the American Society of Transplant Surgeons [17]. Sixty-seven centres participated, and 66 of them stated that they used the BMI range of $35-45$ as the upper limit to initiate an evaluation 
as a selection criterion for KT. Moreover, most of the centres recommended weight loss when BMI was over 35 .

\section{Access to KT}

After being included in the waiting list, there are different waiting times until receiving a KT depending on the BMI. This effect was analysed retrospectively by Gill et al. [18] with data from the US Renal Data System including 702,456 incident ESRD patients. The authors also showed differences depending on gender. Women with BMI > 25 presented a lower likelihood to undergo KT, but men with BMI between 25 and 34.9 were more likely to be transplanted. The reason for these differences is unknown. Moreover, Segev et al. [19] quantified the association between BMI and waiting time for KT, and they concluded that obese patients have lower likelihood of receiving a $\mathrm{KT}$ than normal weight patients (obese patients: $2-7 \%$ lower likelihood, severely obese patients: $24-$ $28 \%$ lower likelihood, and morbidly obese patients: $42-$ $44 \%$ lower likelihood). In a multivariate analysis (considering age, diabetes, BMI, congestive heart failure, cancer, albuminaemia level, and type of dialysis) of a prospective cohort of the French Renal Epidemiology and Information Network Registry [20], patients with a BMI $>30 \mathrm{~kg} /$ $\mathrm{m}^{2}$ at the initiation of dialysis were less likely to receive a KT.

\section{Weight Loss of Potential Candidates}

Although obese patients have better results in HD, obesity has a completely different effect on patients waiting for a KT: lower access to KT and more complications after KT than non-obese patients. Recently, Harhay et al. [21] published a retrospective cohort study using the National Organ Procurement and Transplantation Network data. They included all recipients of the deceased donor in the USA between 2004 and $2014(n=94,465)$. They showed that patients who lost $\geq 10 \%$ of their basal weight in the waiting list had worse results in terms of days of hospitalization and patient or graft survival. The main limitation of this study is that the authors did not evaluate if weight loss was intentional. In the same lines, in 2012, Molnar et al. [22] analysed data from the Scientific Registry of Transplant Recipients including patients on HD and in the waiting list for KT from July 2001 to June 2007 $(n=14,632)$. They observed that those individuals that lost $>5 \mathrm{~kg}$ while on the waiting list had a $20 \%$ increased mortality risk compared to patients who had a stable weight. The main limitations of this study are that authors did not evaluate if weight loss was intentional, and that they excluded patients who were finally transplanted. In contrast, Huang et al. [23] analysed data from the OPTN/ UNOS database with the aim of analysing post-transplant survival outcomes and of exploring whether a survival benefit from pre-transplant weight loss among patients with BMI $>30 \mathrm{~kg} / \mathrm{m}^{2}$ was found. They did not find differences in patient or graft survival. All these studies present short-term results (mean follow-up 6 months and 4 years, respectively).

\section{Pharmacological Treatment}

There are few studies in CKD and ESRD population regarding pharmacological interventions. Orlistat is a locally acting gastrointestinal lipase inhibitor that inhibits gastric and pancreatic lipases and reduces the absorption of dietary fats. It has been related with hyperoxaluria, nephrocalcinosis, acute kidney injury, and worsening of CKD [24], and for this reason, its use on CKD patients is very limited. On the other hand, lorcaserin is a selective agonist of the 5-hydroxytryptamine $2 \mathrm{C}$ serotonin receptor effective and safe for weight loss, improves glycaemic control, and reduces persistent new or worsening albuminuria and the incidence and worsening of CKD [25].

Although glucagon-like peptide-1 analogues were initially developed for treatment of type 2 diabetes mellitus, liraglutide has been approved for obesity treatment in non-diabetic patients [26]. Liraglutide was associated with clinically meaningful weight loss, concurrent reductions in glycaemic variables, reduction in the risk of diabetes and CVRF, including waist circumference and blood pressure, and improvement in health-related quality of life [26], but according to the newly published KDIGO guidelines [27], there are limited data for use of glucagon-like peptide- 1 analogues in severe CKD. In a small randomized clinical trial on ESRD patients, it has been suggested that dose reduction and prolongation of the titration period may be advisable [28]. Further studies are needed to address pharmacological treatment in this population.

\section{Bariatric Surgery}

Many patients would not be able to achieve weight loss with medical recommendations, and some clinicians may consider bariatric surgery (BS). Some meta-analyses demonstrate superior efficacy of BS compared to medical therapy in achieving sustained weight loss in obese patients without ESRD [29]. The main question is when is it better to perform the BS: before or after KT. The published experience of BS in KT candidates is based on case reports showing that it is safe and with good short-term outcomes. Andalib et al. [30] observed a higher baseline 
risk profile in dialysis-dependent compared to non-dialysis-dependent patients with BS and found higher 30-day mortality and morbidity rates in patients on dialysis. However, after adjusting for confounding factors, dependence on dialysis was not found to be an independent predictor of major morbidity. Recently, some groups [31, 32] have published a series of patients comparing the outcomes of BS in ESRD potentially eligible for KT versus normal renal function patients, and this treatment allows similar weight loss in both groups. Some other authors have published a small series of patients that undergo laparoscopic BS techniques before KT, and they concluded that BS is a safe and effective strategy; however, no longterm data were analysed $[33,34]$.

Obesity may lead to altered phamacokinetics of many drugs. Little is known about how BS impacts on the pharmacokinetics of tacrolimus and mycophenolate. Some authors described that dose modification of immunosuppressants after BS may not be necessary aside from standard therapeutic drug monitoring [35]. However, the modified gastrointestinal anatomy after BS may lead to pharmacokinetic alterations in the absorption of immunosuppressants. There are scarce data-related outcomes of BS and the safety and feasibility of maintaining immunosuppression and graft safety among solid organ-transplanted patients. Yemini et al. [35] described an improvement in comorbidities and an increase of immunosuppressive stability among all patients. These data suggest that BS ensures good immunosuppressive maintenance together with significant weight loss and improvement in comorbidities without serious graft rejection or dysfunction.

\section{Obese KT Recipients' Outcomes}

Short-Term Outcomes

Several studies have evaluated short-term outcomes of $\mathrm{KT}$ in obese recipients (Table 1). Four meta-analyses analysing KT outcomes in obese recipients, including up to 209,000 patients, have been published $[36-38,44]$. The majority of the included studies showed worst short-term outcomes in obese compared to normal weight recipients. In 2015, Lafranca et al. [37] analysed perioperative complications in their meta-analysis. They found a higher prevalence of wound infections and dehiscence (RR 3.13 [CI, 2.08-4.71; $p<0.001]$ and RR 4.85 [CI, 3.25-7.25; $p<0.001$ ], respectively), incisional hernia (RR 2.72; CI, $1.05-7.06 ; p=0.04)$, and a higher hospital length (2.31 days; CI, $0.93-3.69 ; p=0.001$ ) in obese population. Aziz et al. [42] found that wound complications were associated with an increased length of hospitalization and a higher risk for rehospitalization.

Obesity in Renal Transplantation
Most studies have analysed the risk of delayed graft function (DGF), defined as the need for dialysis in the first week after transplantation. Three of the 4 meta-analyses show a higher risk of DGF in BMI $\geq 30 \mathrm{~kg} / \mathrm{m}^{2}$ with different RR depending on the study: RR of 1.41 [36] or RR of 1.52 [37] or OR of 1.76 [38]. More recently, large population studies have reported similar results $[42,43]$.

Two of the aforementioned meta-analyses also studied acute rejection with controversial results. Nicoleto et al. [36] did not find an increased risk of rejection in pre-KT obese patients after analysing 11 studies. In contrast, Lafranca et al. [37] in a more recent meta-analysis that considered 22 studies (including the 11 studies analysed by Nicoleto) described a higher acute rejection rate in high BMI $\left(\geq 30 \mathrm{~kg} / \mathrm{m}^{2}\right)$ recipients with an overall RR 1.17 (CI, $\left.1.01-1.37 ; p=0.04, I^{2}=38 \% ; p=0.04\right)$. The authors suggested that the inflammatory state associated with obesity could increase alloreactivity. An alternative hypothesis could be the tacrolimus pharmacokinetic abnormalities associated with obesity. Flabouris et al. [45] studied the association between obesity and acute rejection, and they did not find an increased risk of acute rejection in obese patients after adjusting for dosing of immunosuppression. However, further studies are needed to ascertain the effect of obesity on acute rejection.

\section{Long-Term Outcomes}

Table 2 summarizes long-term outcomes. In terms of long-term results, graft survival was meta-analysed by Lafranca et al. [37] at different time points: at 1 year $(24$ studies), at 2 years (11 studies), and at 3 years (13 studies), and they described better results in lower BMI groups in all time points $\left(\mathrm{RR}=0.97\right.$ [CI, 0.96-0.99; $p<0.001, I^{2}=$ $11 \% ; p=0.32$ ], $\mathrm{RR}=0.95$ [CI, 0.93-0.98; $p=0.002$ ], and $\mathrm{RR}=0.95$ [CI, 0.91-0.98; $p=0.006$ ], respectively). Seven of the included studies performed a regression analysis including BMI as a risk factor for graft loss, and they did not find a statistically significant relation between BMI and graft survival (HR $1.00\left[\mathrm{CI}, 0.96-1.04 ; p=0.98, I^{2}\right.$ $54 \% ; p=0.04])$.

More recently, other retrospective studies have been published. In 2019, Mehta et al. [46] analysed $610 \mathrm{KT}$ recipients, and they did not find any relation between graft or patient survival and BMI at 3 years of follow-up. One year before, Liese et al. [39] observed that graft survival at 4 years in BMI groups of $\leq 29.9 \mathrm{~kg} / \mathrm{m}^{2}$ or $30-34.9 \mathrm{~kg} / \mathrm{m}^{2}$ was approximately $90 \%$, compared to the BMI $\geq 35 \mathrm{~kg} / \mathrm{m}^{2}$ group with a survival of only $77.5 \%$. A Turkish group published data of 561 recipients from living donors, and they observed that obesity during the first year after trans- 


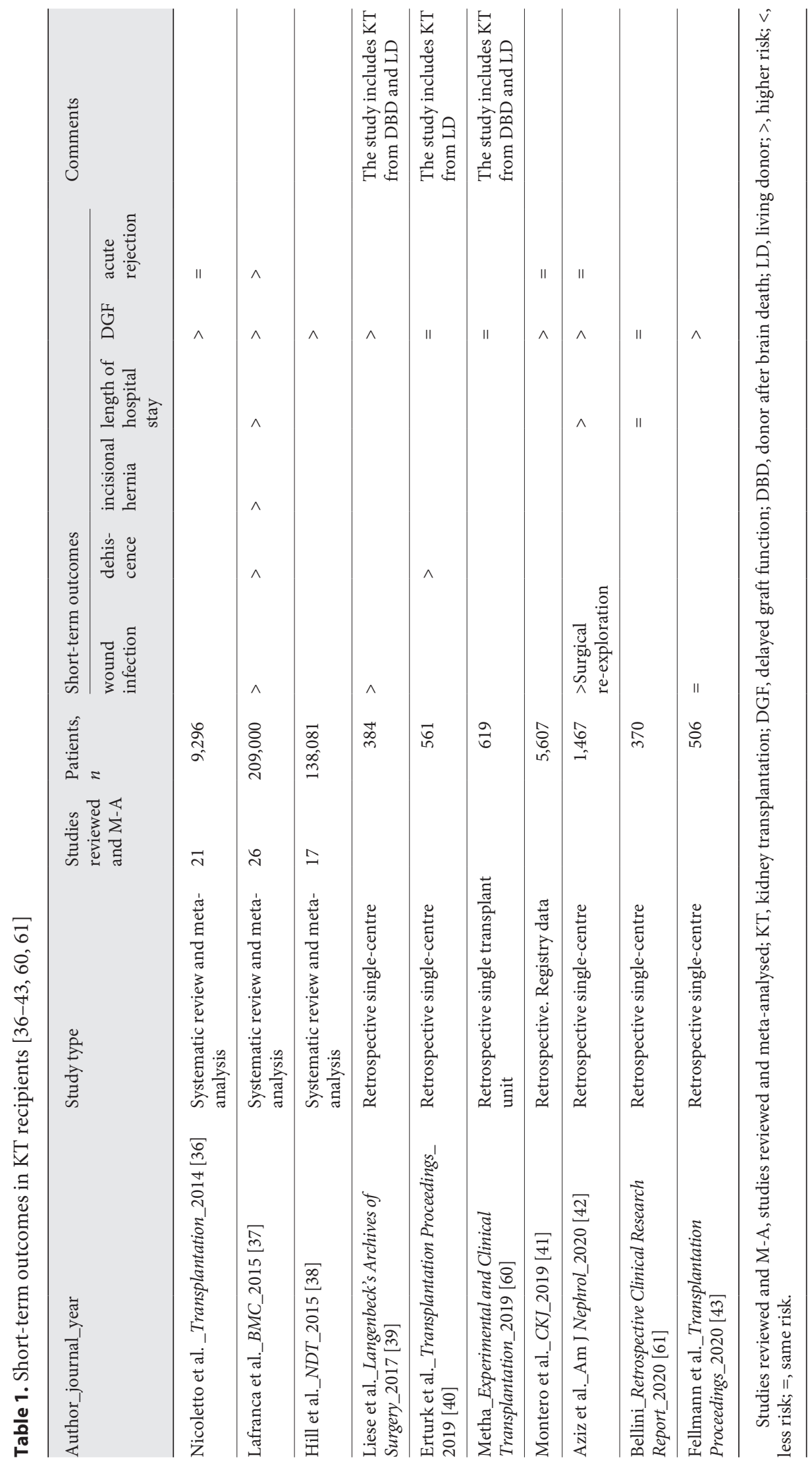




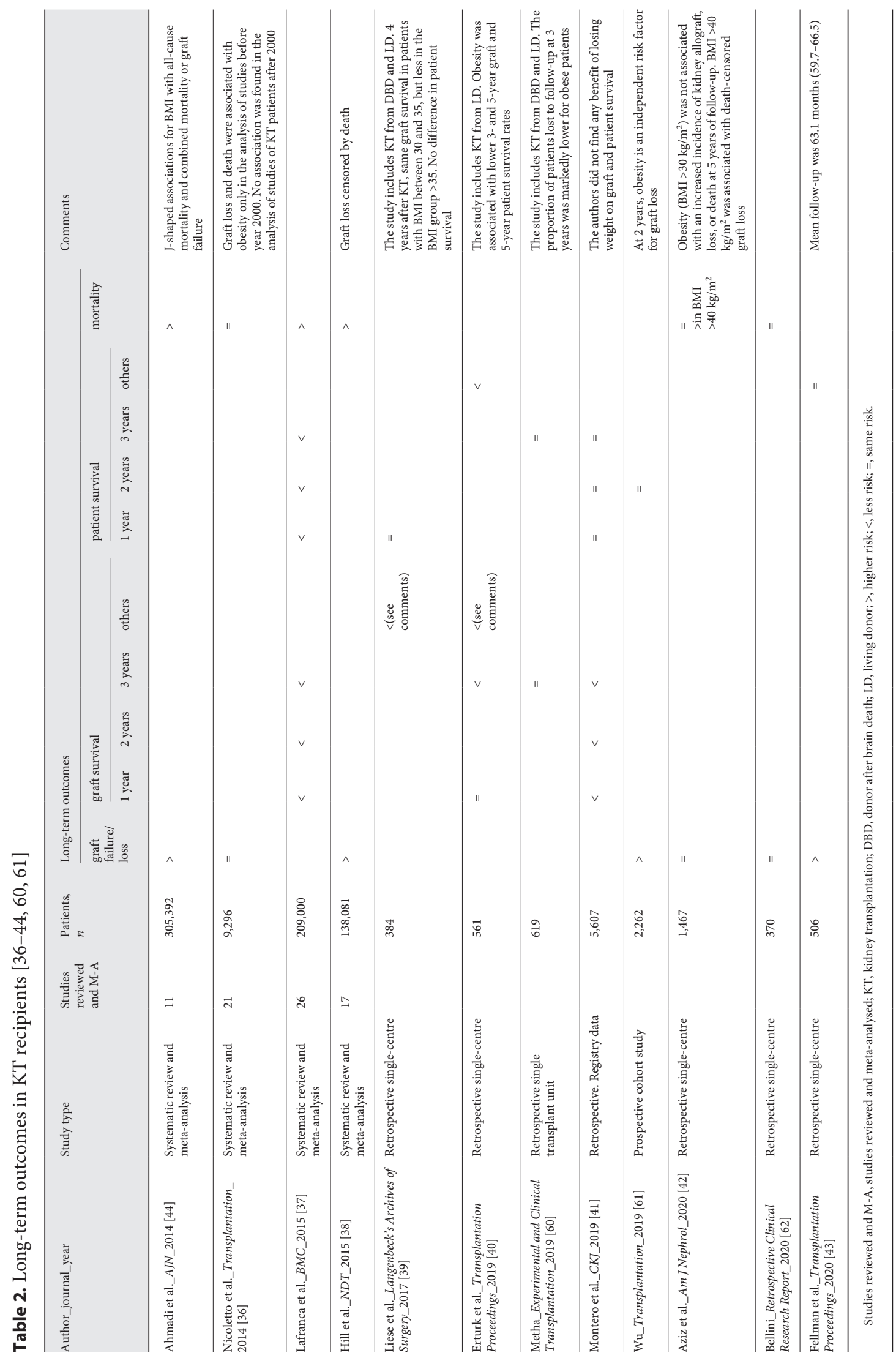


plant was associated with lower 3- and 5-year graft and 5 -year patient survival rates [40]. In terms of patient survival, Ahmadi et al. [44] reported that BMI and all-cause mortality followed a reversed J-shaped curve, presenting a higher all-cause mortality in underweight and obese population compared to normal BMI recipients. In contrast, the rest of the published meta-analyses [36-38] did not find differences in mortality when BMI was adjusted to other covariables. Other recent studies $[39,46]$ neither found differences in terms of patient survival related to BMI.

There are several reasons accounting for the increased risk of graft loss in obese KT recipients. Obesity can affect kidney haemodynamics, resulting in high renal plasma flow and glomerular filtration rate and increased filtration fraction [47]. Obesity is related to development of hyperfiltration and proteinuria leading to glomerulosclerosis with a consequent reduction in glomerular filtration rate [47]. Obesity is a risk factor for DGF, and DGF increases the risk of kidney fibrosis and graft loss. Endocrine and immunological functions of adipose tissue could account for higher levels of pro-inflammatory cytokines in obese patients, which may mediate glomerular injury and contribute to renal damage [47]. An alternative hypothesis could be that pharmacokinetic abnormalities related with obesity predispose to immunologically mediated graft injury due to sub-therapeutic immunosuppression [48].

There are few studies that evaluate post-transplant weight variations. Kurnatowska et al. [49], evaluated changes of BMI every 2 months of $92 \mathrm{KT}$ recipients for 3 years. They observed an increase of BMI in most of the patients, with higher weight gain in pre-KT normal weight compared to obese or overweight recipients. They also observed that patients with BMI $\geq 25$ after KT had higher albuminuria and worse graft function than those with normal BMI. Montero et al. [41] studied 5,607 KT recipients with 9.3 years of follow-up, and they found worse renal function and short-term graft survival outcomes in obese population, without benefits of losing weight after KT. The possible long-term benefits of losing weight for graft function and survival may be jeopardized by short-term obesity-related complications, particularly DGF. They suggested that it is necessary to focus on losing weight before KT.

\section{Impact of Kidney Donor Obesity}

KT from Obese Deceased Donors

At the same time, the obesity epidemic worsens in general population, with the number of obese potential kid- ney donors increasing [50]. Concerning recipient outcomes, Gore et al. [51] analysed the UNOS database which includes data from $>19,000 \mathrm{KT}$ recipients with donor BMI information from 1997 to 1999 . They found that underweight, overweight, obese, and morbidly obese donors were an independent predictor of DGF compared with normal weight donors in a multivariate analysis, and donor BMI was not associated with graft survival on univariate analysis.

Data from 100,327 recipients of deceased donor kidneys between 1997 and 2010 from the Scientific Registry of Transplant Recipients were examined by Ortiz et al. [52], and they did not find significant increased risk of graft loss or mortality for donors with BMI $<45 \mathrm{~kg} / \mathrm{m}^{2}$. However, BMI $\geq 45 \mathrm{~kg} / \mathrm{m}^{2}$ was independently associated with $84 \%$ greater likelihood of graft loss. Moreover, they described an increased risk of DGF in recipients of an obese donor kidney without differences in terms of acute rejection. Another study published using the SRTR database [53] studied a cohort of $115,124 \mathrm{KT}$ recipients and concluded that the combination of size (recipient $>30 \mathrm{~kg}$ ) and gender mismatch was associated with a higher risk of allograft failure.

\section{Living Donors}

Obesity has been a relative contraindication to living kidney donation. Obese donors have more intraoperative risks and short- and long-term detrimental effects [54]. Obesity is a risk factor for hypertension, diabetes mellitus, and chronic kidney disease [55] after nephrectomy.

However, the trend of an increasing prevalence of obesity in the general population [1] is mirrored among donors, so surgeons are acquiring more competencies in managing these surgeries with more operation comfort. Taler et al. [56] analysed 8,951 live kidney donations (from 1963 to 2007) and described that obesity increased over time from $8 \%(1963-1974)$ to $26 \%(1997-2007)$ as well as donor age, hypertension, and glucose intolerance prevalence. Locke et al. [57] performed a national study including 119,769 living kidney donors, and they concluded that although the absolute risk of ESRD after donation was low, donor obesity was independently associated with a 1.9-fold increased risk of ESRD in 20 years after kidney donation compared to non-obese donors. These results are particularly relevant for young kidney donor candidates.

As we have previously mentioned, some authors have studied the mechanisms that explain how obesity could be related with ESRD. Moreover, hyperfiltration state associated with obesity can be aggravated by nephrectomy 


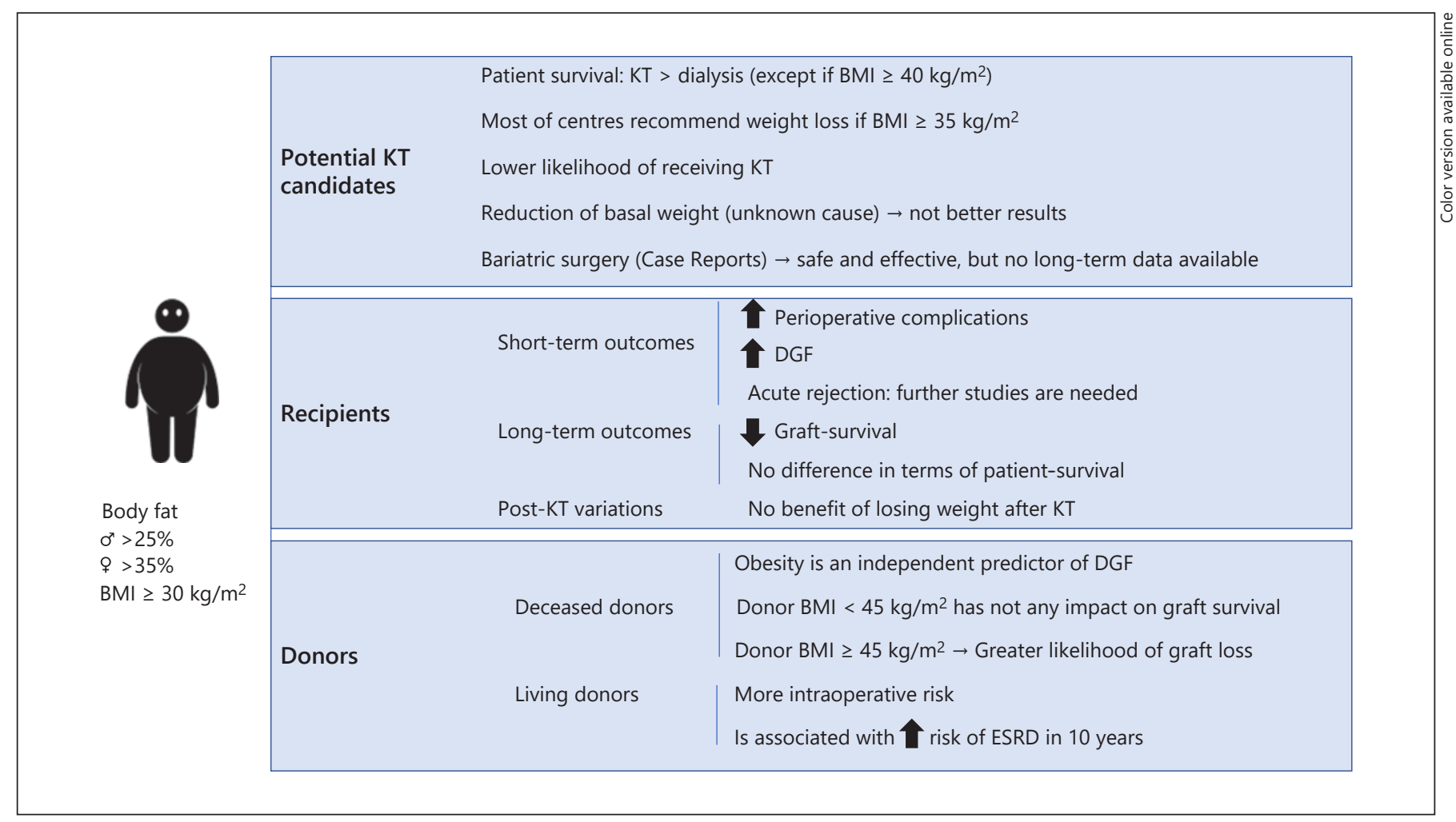

Fig. 1. Summary table. Impact of obesity in KT: potential candidates, recipients, and donors. KT, kidney transplantation; DGF, delayed graft function; ESRD, end-stage renal disease; BS, bariatric surgery.

causing "true" glomerular hypertension. Interestingly, Praga et al. [58] have described an increased incidence of proteinuria and CKD after many years of nephrectomy in obese compared to non-obese patients. The authors suggest that the kidney donor could be a comparable clinical condition to their study population. In terms of histological changes, Rea et al. [59] reported a large glomerular surface area and increased arterial hyalinosis in kidney biopsies from obese living donors.

\section{Recommendations and Future Directions}

Although obesity is associated with early and late postKT complications, several studies have demonstrated that KT improves ESRD obese patient survival [11]. It is also well known that this benefit disappears in patients with BMI $>40 \mathrm{~kg} / \mathrm{m}^{2}[11,12]$ (Fig. 1).

Although the majority of the authors use BMI to classify patients and most of the international guidelines recommend to lose weight until $\mathrm{BMI}<30$, it makes no sense to use a unique exclusion criterion, particularly in patients with $\mathrm{BMI}<40 \mathrm{~kg} / \mathrm{m}^{2}$. It is important to individualize the risk and to consider weight distribution, body shape, and other factors that could increase weight such as body fluid accumulation and muscle mass. On the other hand, recent studies showed no advantage of losing weight after KT, thus suggesting that interventions should be performed before transplantation. However, clinical trials are needed to demonstrate that such intervention reduces the post-KT complications. Meanwhile, public health campaigns to highlight the importance of self-care, increasing exercise, healthy diet, and weight loss, in CKD population should be reinforced.

\section{Acknowledgments}

We thank the CERCA Program/Generalitat de Catalunya and the ISCIII RETICS RedinRen RD16/0009/0003 for institutional support.

\section{Statement of Ethics}

Ethical approval was not required as this article is a review of available studies. 


\section{Conflict of Interest Statement}

The authors confirm that this article content has no conflicts of interest.

\section{Funding Sources}

There is no funding source to declare.

\section{Author Contributions}

Maria Quero, Nuria Montero, Inés Rama, Sergi Codina and Carlos Couceiro drafted the manuscript and revised the article critically. Josep M. Cruzado designed the review, drafted the manuscript, and revised the article critically.

\section{References}

1 World Health Organization. Obesity and overweight [Internet]. 2018.

2 Hoogeveen EK. Re: effect of obesity on the outcome of kidney transplantation: a 20-year follow-up. Transplantation. 2011;91(8):86974.

3 Kramer HJ, Saranathan A, Luke A, DurazoArvizu RA, Guichan C, Hou S, et al. Increasing body mass index and obesity in the incident ESRD population. J Am Soc Nephrol. 2006;17(5):1453-9.

4 Neale J, Smith AC. Cardiovascular risk factors following renal transplant. World J Transplant. 2015;5(4):183

5 Zoccali C, Torino C, Tripepi G, Tripepiand G, Mallamaci F. Assessment of obesity in chronic kidney disease: what is the best measure? Curr Opin Nephrol Hypertens. 2012;21(6): 641-6.

6 Okorodudu DO, Jumean MF, Montori VM, Romero-Corral A, Somers VK, Erwin PJ, et al. Diagnostic performance of body mass index to identify obesity as defined by body adiposity: a systematic review and meta-analysis. Int J Obes. 2010;34(5):791-9.

7 Perreault L. Obesity in adults: Prevalence, screening, and evaluation - UpToDate [Internet]. 2020.

8 Marra M, Sammarco R, De Lorenzo A, Iellamo F, Siervo M, Pietrobelli A, et al. Assessment of body composition in health and disease using bioelectrical impedance analysis (bia) and dual energy $\mathrm{x}$-ray absorptiometry (dxa): a critical overview. Contrast Media Mol Imaging. 2019;2019:1.

9 Von Düring ME, Jenssen T, Bollerslev J, Åsberg A, Godang K, Eide IA, et al. Visceral fat is better related to impaired glucose metabolism than body mass index after kidney transplantation. Transpl Int. 2015;28(10):1162-71.

10 Kalantar-Zadeh K, Kopple JD, Kilpatrick RD, McAllister CJ, Shinaberger CS, Gjertson DW, et al. Association of morbid obesity and weight change over time with cardiovascular survival in hemodialysis population. Am J Kidney Dis. 2005;46(3):489-500.

11 Gill JS, Lan J, Dong J, Rose C, Hendren E, Johnston O, et al. The survival benefit of kidney transplantation in obese patients. Am J Transplant. 2013;13(8):2083-90.
12 Dudley C, Harden P. Renal association clinical practice guideline on the assessment of the potential kidney transplant recipient. Neph ron Clin Pract. 2011;118(Suppl 1):c209-24.

13 Abramowicz D, Cochat P, Claas FH, Heemann U, Pascual J, Dudley C, et al. European Renal Best Practice Guideline on kidney donor and recipient evaluation and perioperative care. Nephrol Dial Transplant. 2015; 30(11):1790-7.

14 KDIGO. KDIGO-Evaluation and management of candidates for KTX-draft-not final! Development. 2018 Oct.

15 Campbell S, Pilmore H, Gracey D, Mulley W Russell C, McTaggart S. KHA-cari guideline: recipient assessment for transplantation. $\mathrm{Ne}-$ phrology. 2013;18(6):455-62.

16 Stenvinkel P, Ikizler TA, Mallamaci F, Zoccali C. Obesity and nephrology: results of a knowledge and practice pattern survey. Nephrol Dial Transplant. 2013;28(Suppl 4): iv99-104.

17 Pondrom S. How big is too big? Am J Transplant. 2012;12:1663-4.

18 Gill JS, Hendren E, Dong J, Johnston O, Gill J. Differential association of body mass index with access to kidney transplantation in men and women. Clin J Am Soc Nephrol. 2014; 9(5):951-9.

19 Segev DL, Simpkins CE, Thompson RE Locke JE, Warren DS, Montgomery RA. Obesity impacts access to kidney transplantation. J Am Soc Nephrol. 2008;19(2):349-55.

20 Hannedouche T, Lassalle M, Massy A. Obesity and access to kidney transplantation in patients starting dialysis: a prospective cohort study. PLoS One. 2017;12:e0176616.

21 Harhay MN, Ranganna K, Boyle SM, Brown AM, Bajakian T, Levin Mizrahi LB, et al. Association between weight loss before deceased donor kidney transplantation and posttransplantation outcomes. Am J Kidney Dis. 2019; 74(3):361-72.

22 Molnar MZ, Streja E, Kovesdy CP, Bunnapradist S, Sampaio MS, Jing J, et al. Associations of body mass index and weight loss with mortality in transplant-waitlisted maintenance hemodialysis patients. Am J Transplant. 2011; 11(4):725-36.

23 Huang E, Bunnapradist S. Pre-transplant weight loss and survival after kidney transplantation. Am J Nephrol. 2015;41(6):448-55.
24 Coutinho AK, Glancey GR. Orlistat, an under-recognised cause of progressive renal impairment. Nephrol Dial Transplant. 2013; 28(Suppl 4):iv172-4.

25 Scirica BM, Bohula EA, Dwyer JP, Qamar A, Inzucchi SE, McGuire DK, et al. Lorcaserin and renal outcomes in obese and overweight patients in the CAMELLIA-TIMI 61 trial. Circulation. 2019;139(3):366-75.

26 Pi-Sunyer X, Astrup A, Fujioka K, Greenway F, Halpern A, Krempf M, et al. A randomized, controlled trial of $3.0 \mathrm{mg}$ of liraglutide in weight management. N Engl J Med. 2015; 373(1):11-22.

27 Coates PT, Devuyst O, Wong G, Okusa M, Oliver J, York N, et al. International. KDIGO guidel 2020 diabetes CKD. 2020;98(4).

28 Idorn T, Knop FK, Jørgensen MB, Jensen T, Resuli M, Hansen PM, et al. Safety and efficacy of liraglutide in patients with type 2 diabetes and end-stage renal disease: an investigator-initiated, placebo-controlled, doubleblind, parallel-group, randomized trial Diabetes Care. 2016;39(2):206-13.

29 Lesage J, Gill JS. Management of the obese kidney transplant candidate. Transplant Rev. 2017;31(1):35-41.

30 Andalib A, Aminian A, Khorgami Z, Navaneethan SD, Schauer PR, Brethauer SA. Safety analysis of primary bariatric surgery in patients on chronic dialysis. Surg Endosc. 2016; 30(6):2583-91.

31 Gaillard M, Tranchart H, Beaudreuil S, Lebrun A, Voican CS, Lainas P, et al. Laparoscopic sleeve gastrectomy for morbid obesity in renal transplantation candidates: a matched case-control study. Transpl Int. 2020;33(9): 1061-70.

32 Dobrzycka M, Proczko-Stepaniak M, Kaska Ł, Wilczyński M, Dębska-Ślizień A, Kobiela J. Weight loss after bariatric surgery in morbidly obese end-stage kidney disease patients as preparation for kidney transplantation. matched pair analysis in a high-volume bariatric and transplant center. Obes Surg. 2020 30(7):2708-14.

33 Yemini R, Nesher E, Carmeli I, Winkler J, Rahamimov R, Mor E, et al. Bariatric surgery is efficacious and improves access to transplantation for morbidly obese renal transplant candidates. Obes Surg. 2019;29(8):2373-80. 
34 Bouchard P, Tchervenkov J, Demyttenaere S, Court O, Andalib A. Safety and efficacy of the sleeve gastrectomy as a strategy towards kidney transplantation. Surg Endosc. 2020;34(6): 2657-64.

35 Yemini R, Nesher E, Winkler J, Carmeli I, Azran C, Ben David M, et al. Bariatric surgery in solid organ transplant patients: long-term follow-up results of outcome, safety, and effect on immunosuppression. Am J Transplant. 2018;18(11):2772-80.

36 Nicoletto BB, Fonseca NK, Manfro RC, Gonçalves LF, Leitão CB, Souza GC. Effects of obesity on kidney transplantation outcomes: a systematic review and meta-analysis. Transplantation. 2014;98(2):167-76.

37 Lafranca JA, IJermans JN, Betjes MG, Dor FJ Body mass index and outcome in renal transplant recipients: a systematic review and meta-analysis. BMC Med. 2015;13(1):111.

38 Hill CJ, Courtney AE, Cardwell CR, Maxwell AP, Lucarelli G, Veroux M, et al. Recipient obesity and outcomes after kidney transplantation: a systematic review and meta-analysis. Nephrol Dial Transplant. 2015;30(8):140311.

39 Liese J, Bottner N, Büttner S, Reinisch A, Woeste $G$, Wortmann $M$, et al. Influence of the recipient body mass index on the outcomes after kidney transplantation. Langenbecks Arch Surg. 2018;403(1):73-82.

40 Erturk T, Berber I, Cakir U. Effect of obesity on clinical outcomes of kidney transplant patients. Transplant Proc. 2019;51(4):1093-5.

41 Montero N, Quero M, Arcos E, Comas J, Rama I, Lloberas N, et al. Effects of body weight variation in obese kidney recipients: a retrospective cohort study. Clin Kidney J. 2019;1-9.

42 Aziz F, Ramadorai A, Parajuli S, Garg N, Mohamed M, Mandelbrot DA, et al. Obesity: an independent predictor of morbidity and graft loss after kidney transplantation. Am J Nephrol. 2020;51(8):615-23.

43 Fellmann M, Balssa L, Clément E, Frey P, Frontczak A, Bernardini S, et al. Effects of obesity on postoperative complications and graft survival after kidney transplantation. Transplant Proc Elsevier Inc. 2020;7:1-7.
44 Ahmadi S-F, Zahmatkesh G, Streja E, Molnar MZ, Rhee CM, Kovesdy CP, et al. Body mass index and mortality in kidney transplant recipients: a systematic review and meta-analysis. Am J Nephrol. 2014;40(4):315-24.

45 Flabouris K, Chadban S, Ladhani M, Cervelli $\mathrm{M}$, Clayton P. Body mass index, weight-adjusted immunosuppression and the risk of acute rejection and infection after kidney transplantation: a cohort study. Nephrol Dial Transplant. 2019;34(12):2132-43.

46 Mehta A, Ghazanfar A, Marriott A, Morsy M. Where to draw the line in surgical obesity for renal transplant recipients: an outcome analysis based on body mass index. Exp Clin Transplant. 2019;17(1):37-41.

47 Ducloux D, Kazory A, Simula-Faivre D, Chalopin JM. One-year post-transplant weight gain is a risk factor for graft loss. Am J Transplant. 2005;5(12):2922-8.

48 Khwaja A, El-Nahas M. Transplantation in the obese: separating myth from reality. Nephrol Dial Transplant. 2012;27(10):37325 .

49 Kurnatowska I, Małyska A, Wysocka K, Mazur K, Krawczyk J, Nowicki M. Long-term effect of body mass index changes on graft damage markers in patients after kidney transplantation. Ann Transplant. 2016;21:626-31.

50 Hassanain M, Simoneau E, Doi SA, Aljiffry M, Aloraini A, Madkhali A, et al. Trends in brain-dead organ donor characteristics: a 13year analysis. Can J Surg. 2016;59(3):154-60.

51 Gore JL, Pham PT, Danovitch GM, Wilkinson AH, Rosenthal JT, Rosenthal JT, et al. Obesity and outcome following renal transplantation. Am J Transplant. 2006;6(2):35763.

52 Ortiz J, Gregg A, Wen X, Karipineni F, Kayler LK. Impact of donor obesity and donation after cardiac death on outcomes after kidney transplantation. Clin Transplant. 2012;26(3): E284-92.

53 Miller AJ, Kiberd BA, Alwayn IP, Odutayo A, Tennankore KK. Donor-recipient weight and sex mismatch and the risk of graft loss in renal transplantation. Clin J Am Soc Nephrol. 2017; 12(4):669-76.
54 Heimbach JK, Taler SJ, Prieto M, Cosio FG, Textor SC, Kudva YC, et al. Obesity in living kidney donors: clinical characteristics and outcomes in the era of laparoscopic donor nephrectomy. Am J Transplant. 2005;5(5): 1057-64.

55 Serrano OK, Sengupta B, Bangdiwala A, Vock DM, Dunn TB, Finger EB, et al. Implications of excess weight on kidney donation: longterm consequences of donor nephrectomy in obese donors. Surgery. 2018;164(5):1071-6.

56 Taler SJ, Messersmith EE, Leichtman AB, Gillespie BW, Kew CE, Stegall MD, et al. Demographic, metabolic, and blood pressure characteristics of living kidney donors spanning five decades. Am J Transplant. 2013;13(2): $390-8$.

57 Locke JE, Reed RD, Massie A, MacLennan PA, Sawinski D, Kumar V, et al. Obesity increases the risk of end-stage renal disease among living kidney donors. Kidney Int. 2017;91(3):699-703.

58 Praga M, Hernández E, Herrero JC, Morales E, Revilla Y, Díaz-González R, et al. Influence of obesity on the appearance of proteinuria and renal insufficiency after unilateral nephrectomy. Kidney Int. 2000;58(5):2111-8.

59 Rea DJ, Heimbach JK, Grande JP, Textor SC, Taler SJ, Prieto M, et al. Glomerular volume and renal histology in obese and non-obese living kidney donors. Kidney Int. 2006;70(9): 1636-41.

60 Metha A, Ghazanfar A, Marriott A, Morsy M. Where to Draw the Line in Surgical Obesity for Renal Transplant Recipients: An Outcome Analysis Based on Body Mass Index. Exp Cli Transplant. 2019 Feb;17(1):37-41.

61 Wu DA, Robb ML, Forsythe J L R, Bradley C, Cairns J, Draper H, et al. Recipient Comorbidity and Survival Outcomes after Kidney Transplantation: A UK-Wide Prospective Cohort Study. Transplantation. 2020 Jun;104(6):1246-55.

62 Bellini MI, Koutroutsos K, Nananpragasam H, Deurloo E, Galliford J, Herbert PE. Obesity affects graft function but not graft loss in kidney transplant recipients. J Int Med Res. 2020 Jan;48(1):0300060519895139. 